Research article

\title{
The relationships between therapeutic alliance and internalizing and externalizing symptoms in Trauma-Focused Cognitive Behavioral Therapy
}

\author{
Karina P.M. Zorzella, Robert T. Muller*, Robert A. Cribbie \\ Department of Psychology, York University, Toronto, Ontario, Canada
}

\section{A R T I C L E I N F O}

\section{Article history:}

Received 7 April 2015

Received in revised form 28 July 2015

Accepted 3 August 2015

Available online 1 September 2015

\section{Keywords:}

Alliance

TF-CBT

Psychopathology

Internalizing

Externalizing

Outcome

\begin{abstract}
A B S T R A C T
Therapeutic alliance has been considered an important factor in child psychotherapy and is consistently associated with positive outcomes. Nevertheless, research on alliance in the context of child trauma therapy is very scarce. This study examined the relationships between child therapeutic alliance and psychopathology in an empirically supported child trauma therapy model designed to address issues related to trauma with children and their caregivers. Specifically, we examined the extent to which the child's psychopathology would predict the establishment of a positive alliance early in treatment, as well as the association between alliance and outcome. Participants were 95 children between the ages of 7 and 12 and their caregivers, who went through a community-based Trauma-Focused Cognitive Behavioral Therapy program in Canada. Caregivers filled out the CBCL prior to assessment and following treatment. Children and therapists completed an alliance measure (TASC) at three time points throughout treatment. Symptomatology and child gender emerged as important factors predicting alliance at the beginning of treatment. Girls and internalizing children developed stronger alliances early in treatment. In addition, a strong early alliance emerged as a significant predictor of improvement in internalizing symptoms at the end of treatment. Our findings indicate that symptomatology and gender influence the development of a strong alliance in trauma therapy. We suggest that clinicians should adjust therapeutic style to better engage boys and highly externalizing children in the early stages of therapy.
\end{abstract}

(C) 2015 Elsevier Ltd. All rights reserved.

\section{Introduction}

The importance of a strong therapeutic alliance in the treatment of traumatized children and adolescents has been relatively understudied in comparison to research on traumatized adults, and little is known about the role of alliance on outcomes in child trauma therapies. Alliance has been defined as agreement on therapy goals and tasks, and an emotional bond between client and therapist (Bordin, 1979), and is associated with positive outcomes in adult therapy (Horvath \& Luborsky, 1993; Martin, Garske, \& Davies, 2000) and child and adolescent therapy (Shirk \& Karver, 2003; Shirk, Karver, \&

\footnotetext{
This research was funded by grants to the second author from the Provincial Center of Excellence for Child and Youth Mental Health at the Children's Hospital of Eastern Ontario, and the Hedge Funds Care Canada Foundation.

* Corresponding author.
} 
Brown, 2011). It has been suggested that strong therapeutic alliance is pre-requisite for effective implementation of therapy techniques and tasks and also a curative factor in itself (DiGiuseppe, Linscott, \& Jilton, 1996; Garcia \& Weisz, 2002).

\section{Child Alliance and Trauma}

For developmental reasons, it may be difficult for children to establish a strong therapeutic alliance. Often they do not initiate their own referral to therapy and this may compromise their motivation in treatment and their engagement in the relationship with the therapist (DiGiuseppe et al., 1996; Kendall et al., 2009). While younger children may have a limited understanding of the need for therapy, adolescents may not agree with their parents on the nature of the problems or whether treatment is necessary at all (Green, 2006).

Maltreated children may face additional challenges connecting with their therapists. As a result of traumatic experiences, especially those that occurred within a caregiving relationship, they often struggle to find safety in relationships and perceive others as untrustworthy (Cloitre, Cohen, \& Scarvalone, 2002; Eltz, Shirk, \& Sarlin, 1995). They may be particularly hesitant or unwilling to engage in a therapeutic relationship and their ability to work this through may influence treatment success (Eltz et al., 1995; Ormaugh, Jensen, Wentzel-Larsen, \& Shirk, 2013). Given these challenges, it is crucial to identify potential factors associated with stronger and weaker alliances, as well as the relationship between alliance and treatment outcome.

Maltreated children are at risk for the development of psychopathology (Cicchetti \& Toth, 1995). Childhood maltreatment seems to increase the likelihood of further disruptions in development processes, which may result in a cascade of maladaptation across multiple domains (Masten \& Cicchetti, 2010; McCrory, De Brito, \& Viding, 2010). Maltreated children were found to be at higher risk than their non-maltreated peers for attachment and relationship difficulties, academic failure, and neurobiological alterations (Cicchetti \& Toth, 2005). Adolescents with a history of maltreatment were also found to report higher rates of internalizing and externalizing behaviors when compared with their non-maltreated peers (Mills et al., 2013). Thus, it is reasonable to expect that their presenting difficulties might also interfere with the establishment of a positive therapeutic alliance, especially in early stages of treatment when psychopathology has not yet been fully addressed.

Children's reactions to trauma are frequently reported in the form of PTSD symptoms such as hypervigilance, avoidance, and intrusive thoughts (Finkelhor, Ormorod, Turner, \& Hamby, 2005). In addition, they often present elevated internalizing and externalizing symptoms (Manly, Kim, Rogosch, \& Cicchetti, 2001). There is a high incidence of internalizing problems such as anxiety, depression, withdrawal, and somatic complaints among maltreated children (Bolger \& Patterson, 2001; Manly et al., 2001; Moylan et al., 2010). Similarly, the association between externalizing problems and child maltreatment has been also demonstrated (Manly et al., 2001; Moylan et al., 2010). Common difficulties include aggression, delinquent behaviors, and disruptive behaviors (Manly et al., 2001; Moylan et al., 2010; Teisl \& Cicchetti, 2008).

Studies of broad categories of internalizing and externalizing symptoms in relation to therapeutic alliance are scarce, especially in the field of child trauma. A pilot study on the program investigated in this paper showed that internalizing and externalizing problems were predictors of early alliance (McLewin, 2010), Studies using non-maltreated samples have shown that children with higher externalizing problems reported more therapeutic relationship problems than those with higher internalizing problems and this was associated with higher drop-out from therapy (Garcia \& Weisz, 2002). Research with delinquent adolescents showed that the most severely delinquent youth demonstrated greater difficulty developing a positive therapeutic relationship with staff and those who developed and sustained a positive alliance demonstrated more therapeutic gains and less recidivism (Florsheim, Shotorbani, Guest-Warnick, Barratt, \& Wei-Chin, 2000). It may be that children with more externalizing problems are more oppositional and find it difficult to agree on treatment goals and tasks and engage in the therapeutic relationship. On the other hand, internalizing children seem more willing to engage in the therapeutic relationship than externalizing children to alleviate their internal distress (DiGiuseppe et al., 1996). For example, a study of youth with anxiety disorders revealed a highly positive alliance, with limited variability in scores (Kendall, 1994). Another study of CBT for youth anxiety indicated higher anxiety symptoms predicted higher early alliance scores. Nevertheless, depressive symptoms did not appear to affect early alliance scores (Chu, Skriner, \& Zandberg, 2014). The current investigation examined the relationship between internalizing and externalizing symptomatology and therapeutic alliance at the initial stages of trauma treatment.

\section{Alliance and Outcome in Child Trauma Therapy}

In child therapy, therapeutic alliance predicts engagement in therapeutic tasks (Chiu, McLeod, Har, \& Wood, 2009; Chu et al., 2004) and successful treatment outcomes (Kazdin \& Durbin, 2012; Liber et al., 2010; McLeod \& Weisz, 2005; Shirk \& Karver, 2003; Shirk, Gundmundsen, Kaplinski, \& McMakin, 2008). It may also be a key element to creating motivation for and retention in treatment (Chu et al., 2004). Yet, few studies have examined the relationship between alliance and outcome in child trauma therapies (Eltz et al., 1995; Ormaugh et al., 2013).

Adult trauma research has shown that a strong early alliance in manualized behavioral treatment is associated with improvements following therapy due, in part, to clients' greater engagement in the exposure tasks of treatment (Cloitre, Koenen, Cohen, \& Han, 2002; Cloitre, Stovall-McClough, Miranda, \& Chemtob, 2004; Keller, Zoellner, \& Feeny, 2010). A weak alliance was associated with less positive outcomes (Dalenberg, 2000; Eltz et al., 1995). A study of traumatized youth shows a stronger association with positive outcome in a cognitive behavioral treatment condition (i.e., Trauma Focused Cognitive 
Behavioral Therapy - TF-CBT) than in a treatment as usual condition (Ormaugh et al., 2013), suggesting that a strong alliance promotes active engagement in the TF-CBT tasks, which translates into symptom reduction.

Along with the question of early alliance and outcome in child trauma therapy is the issue of whether positive change in alliance is associated with change in outcome. A study showed that traumatized adolescents showing more positive change in therapeutic alliance displayed greater treatment gains (Eltz et al., 1995). Research with non-traumatized youth suggests that positive change in alliance was associated with a higher rate of psychopathology improvement (Bickman et al., 2012; Florsheim et al., 2000; Hogue, Dauber, Stambaugh, Cecero, \& Liddle, 2006). Similarly, a study of children with anxiety disorders showed that positive changes in child involvement were associated with greater treatment gains (Chu \& Kendall, 2004). In the current study, we investigated the association between alliance and outcome in a cognitive behavioral treatment program for child trauma. Specifically, we examined the relationships among early alliance, improvement in alliance, and outcome following a treatment program utilizing TF-CBT.

\section{The Current Study}

The purpose of the current study was to investigate the relationships between child therapeutic alliance and psychopathology in an empirically supported therapy model designed to address issues related to trauma with children and their caregivers. Our primary goals were to examine whether children's psychopathology predicted alliance early in treatment, and whether early alliance predicted post-therapy change in symptomatology. As a secondary goal, we examined the association between change in alliance and change in symptomatology. We expected that internalizing and externalizing symptoms would predict early alliance as reported by both child and therapist. While higher internalizing symptoms would predict stronger alliances, higher externalizing symptoms would predict weaker alliances. We also expected that early child and therapist alliances would predict improvement in both internalizing and externalizing symptoms. Stronger early alliances would predict greater improvement in symptoms. Additionally, we expected a positive correlation between change in alliance and change in symptomatology at post-treatment.

\section{Method}

\section{Participants}

Participants were 95 children and their caregivers who went through the Healthy Coping Program (Konanur, Muller, Cinamon, Thornback, \&Zorzella, in press; Muller \& Di Paolo, 2008; Muller, Padoin, \& Lawford, 2008); the program is described below. Seventy-four children were female (69.2\%) and thirty-three were male (30.8\%). The children's ages ranged from 7 to 12 $(M=9.58, S D=1.61)$. Children were referred due to sexual abuse $(72.3 \%)$, physical abuse $(21 \%)$, psychological abuse $(16.3 \%)$, neglect (10.4\%), witnessing domestic violence (60\%), death of a caregiver (34\%), and bullying (10.9\%). Children experienced on average 2.47 types of traumas ( $S D=1.35$, range of $1-7$ ) and $36 \%$ percent of perpetrators were caregivers. A total of $27.4 \%$ of the children had a clinical diagnosis at the time of referral, which included a learning disability (10.5\%), ADHD (9.5\%), mood disorder (2.1\%), anxiety disorder (1.1\%), and other non-specified (4.2\%).

The ethnic composition was European-Canadian (38.1\%), African-Canadian (18.1\%), Latin American-Canadian (10.5\%), Asian-Canadian (10.5\%), Aboriginal (1.9\%), and Other (21\%). With respect to religion, 43.4\% were Catholic, $8.5 \%$ were Protestant, 2.8\% were Jewish, 2.8\% were Islamic, $24.5 \%$ designated themselves as "other", and $17.9 \%$ had no religious affiliation. Participating caregivers were predominantly biological or adoptive mothers (83.3\%). The remaining caregivers identified themselves as foster parents (7.5\%), biological or adoptive fathers (7.4\%), and other, made up of one stepfather, one aunt, and one child and youth worker (2.8\%). In terms of family income, $58.1 \%$ earned less than $\$ 40,000$.

Participants were recruited from Boost (formerly known as Toronto Child Abuse Centre) and Peel Children's Centre and included children between the ages of seven and twelve years who had experienced abuse or exposure to violence. The inclusion criteria specified the following conditions: (1) the child had an abuse or trauma experience verified by children's services or police, (2) a non-offending parent or caregiver was willing and able to participate in assessment and treatment, (3) the child and caregiver were fluent in English, (4) the child and/or caregiver did not have an active substance use or psychotic disorder that interfered with functioning, (5) the child was not actively suicidal, (6) the child did not have a documented developmental disorder (e.g., autism), (7) the child and/or caregiver were currently on a stable regimen if taking a psychotropic medication, and (8) the child had not received prior treatment for the trauma or abuse that the referral was based upon. As a compensation for participating in the research, families received $\$ 20$ for each of the first four data collections, and $\$ 30$ for the final data collection.

A total of 159 caregivers were approached by a York University researcher at the initial intake meeting. At pre-assessment, data were available for 107 children but only 95 caregivers completed the study measures. Cases with missing parent-report information were most often due to time constraints that did not allow the parent to complete questionnaires for more than one sibling, or in a few cases due to language barriers. In these cases, although their spoken English was deemed appropriate for participation in therapy, the study measures posed unexpected language comprehension challenges and could not be completed. No participants were excluded from the study due to concerns about caregivers' or children's fluency in English. 
Program

The Healthy Coping is a provincially funded, community-based treatment program that aims to address issues related to trauma with children and their caregivers. It was designed to extend previous clinical research by evaluating the effectiveness of a Trauma-Focused Cognitive Behavioral Therapy program (Cohen, Mannarino, \& Deblinger, 2006) with children who have experienced various forms of trauma, and who were treated in one the seven local community mental health centers providing trauma treatment in the Toronto area.

TF-CBT has received empirical support in reducing trauma and related symptoms in samples of children following treatment (Cohen, Deblinger, Mannarino, \& Steer, 2004; Cohen \& Mannarino, 1998; Deblinger, Mannarino, Cohen, Runyon, \& Steer, 2011; Konanur et al., in press) and at twelve and twenty-four month follow-ups (Cohen, Mannarino, \& Knudsen, 2005; Deblinger, Steer, \& Lippman, 1999). A number of health organizations in the United Stated have given TF-CBT their highest endorsements (see Cary \& McMillen, 2012 for a review).

Participants received an average of 17.67 sessions of TF-CBT ( $S D=7.21$; range of $10-45$ ) over a period between 4 and 12 months. In some cases therapists found that families required more than the suggested number of sessions due to issues that arose during the treatment. As such, these numbers are thought to reflect the variation that exists in typical community settings. Child and parent attended 45-min weekly sessions, each one covering approximately the same material. Child interventions included developing skills in: emotional regulation; cognitive processing; problem-solving; healthy sexuality; and relationship-social skills. The first third of treatment emphasized skill building, followed by the construction of a "trauma narrative" during which they could practice coping skills learned and re-work trauma cognitive distortions. Parent interventions included exploring the caregiver's emotional reactions to the child's abuse or trauma, learning appropriate behavior management skills, and enhancing support of their child. In the latter third of therapy, joint parent-child sessions aimed at improving parent-child communication, providing joint education, and sharing the trauma narrative with the parent. The acronym PRACTICE summarizes the model components: Psychoeducation and Parent skills, $\boldsymbol{R}$ elaxation, $\boldsymbol{A}$ ffective expression and modulation, Cognitive coping and processing, Trauma narrative, In vivo mastery, Enhancing safety. Skills taught in early stages of therapy were the foundation for treatment components addressed later in therapy.

Thirty-four therapists from seven community mental health agencies in the Toronto area participated in the study. Each clinician saw an average of 2.23 clients $(S D=1.61$, range $1-8)$ and each agency serviced an average of 9.57 clients $(S D=4.79$, range 1-16). They were predominantly female therapists holding a Master's degree in social work or psychology with experience working with children with trauma histories. Prior to taking on clinical cases, they were required to read the TFCBT training manual (Cohen et al., 2006), and complete a web-based training program. Therapists attended monthly clinical meetings where they received peer consultation and supervision by psychologists who have worked extensively within the TF-CBT model (i.e., Dr. Amy Hoch and Dr. Melissa Runyon from the CARES Institute in New Jersey). They also attended monthly small focus groups where they received further supervision and feedback on TF-CBT implementation. Since these were independent practitioners whose supervision at their agency was normally limited to case management, the ongoing supervision required in our research represented a unique opportunity for peer supervision. Therapists were also required to complete a self-report adherence checklist following each therapy session to self- monitor model implementation. This system was meant to have an educative role and to help therapists track the progress of their cases and identify and quickly correct potential deviations from the model. Finally, therapists attended TF-CBT training workshops that were organized by the Healthy Coping Project research committee.

\section{Procedure}

This project received university ethics approval, as well as ethics approval by each of the participating agencies. Data were collected from March 2006 through January 2013. From March 2006 to August 2008, participating families were randomly assigned to either a 3-month waitlist control condition, or to an immediate services group. Families were no longer placed in the waitlist control group following August 2008, due to an agency policy change.

Caregivers and children completed several psychopathology measures at four time points: pre-assessment, pretreatment, post-treatment, and six months after the end of treatment. The study includes data on internalizing and externalizing symptoms at pre-assessment and post-therapy as reported by caregivers and alliance data collected from children and therapists at the end of the third and eighth sessions and following the end of therapy.

\section{Measures}

Therapeutic Alliance Scale for Children (TASC; Shirk \& Saitz, 1992). The TASC was used to assess the child's alliance with the therapist. Two versions of TASC, parallel in content and format, were completed by child and therapist. The scale comprises 12 items rated on a 4-point scale ranging from 1 (not like me) to 4 (very much like me). The items ask about the extent to which children perceive their therapist as an ally, like to spend time with their therapist, and feel that they can talk about their problems with their therapist. It has been found to be a reliable instrument, with Cronbach's alphas ranging from .88 to .93 for the child version, and from .94 to .96 for the therapist version (Creed \& Kendall, 2005; Hawley \& Weisz, 2005). Reliability analyses with the current sample showed that the measure has good internal consistency, with alpha coefficients ranging from .75 to .93 . 
Table 1

Descriptive statistics and reliabilities.

\begin{tabular}{|c|c|c|c|c|c|}
\hline & $n$ & Range & $M$ & $S D$ & $\alpha$ \\
\hline Child alliance 1 (session 3 ) & 65 & $30-48$ & 42.52 & 4.85 & .79 \\
\hline Child alliance 2 (session 8 ) & 62 & $25-48$ & 42.31 & 5.12 & .80 \\
\hline Child alliance 3 (post-therapy) & 55 & $31-48$ & 44.38 & 3.74 & .75 \\
\hline Therapist alliance 1 (session 3 ) & 62 & $25-48$ & 38.66 & 5.87 & .89 \\
\hline Therapist alliance 2 (session 8 ) & 60 & $12-48$ & 38.90 & 6.58 & .93 \\
\hline Therapist alliance 3 (post-therapy) & 52 & $21-48$ & 41.15 & 5.57 & .91 \\
\hline Internalizing symptoms (pre-assessment) & 95 & $0-41$ & 14.67 & 8.99 & .88 \\
\hline Externalizing symptoms (pre-assessment) & 95 & $0-48$ & 13.25 & 8.65 & .90 \\
\hline Internalizing symptoms (post-therapy) & 50 & $0-50$ & 10.48 & 9.80 & .90 \\
\hline Externalizing symptoms (post-therapy) & 50 & $0-30$ & 9.52 & 7.53 & .89 \\
\hline
\end{tabular}

Child Behavior Checklist 6-18 (CBCL 6-18; Achenbach \& Rescorla, 2001). The CBCL was used to assess internalizing and externalizing symptoms. It comprises 118 questions, completed by caregivers, measuring various symptoms in children and youth between 6 and 18 years of age. Caregivers rate how true an item is, from 1 (not true) to 3 (very true or often true). Scores can be categorized into Internalizing, Externalizing, and Total Problems. Internalizing questions inquire about problems such as anxiety, depression, withdrawal, and somatic complaints. Externalizing items query problems such as aggression and delinquency. The CBCL has been widely researched and found to be a reliable and valid measure of children's and youth's psychological functioning (Achenbach, Howell, McConaughy, \& Stanger, 1998). The authors report strong internal consistency, with alphas of .90 (Internalizing) and .94 (Externalizing). For our sample, the Cronbach's alphas ranged from .88 to .90 for the Internalizing scale, and from .89 to .90 for the Externalizing scale.

\section{Results}

Data on symptomatology were available for 95 children at pre-assessment and 50 children at post-treatment. Alliance data were available for 65 children (62 with therapist version measure) at session 3, 62 children (60 children with therapist version measure) at session 8 , and 55 children ( 52 children with therapist version measure) at post-therapy (see Table 1 for descriptive statistics). Internalizing and externalizing symptoms represent the raw scores from the CBCL Internalizing and Externalizing scales, respectively. Raw scores were converted to $T$ scores, which ranged from 34 to 87 for internalizing and 34 to 85 for externalizing symptoms at the time of the assessment. All pre-assessment data analyzed included the intent-to-treat sample.

Data were examined for normality and univariate and multivariate outliers. Univariate outliers were identified in the data for internalizing symptoms at post-therapy, externalizing symptoms at pre-assessment, child alliance at sessions 3 and post-therapy, and therapist alliance at post-therapy. Results were not altered upon removal of the outliers, thus they were kept in the analyses. To correct for normality violations in the data corresponding to internalizing symptoms, a logarithmic transformation was performed on both pre-assessment and post-therapy internalizing symptoms variables. Although some normality issues were detected in the alliance data, results remained the same when analyses were conducted with either logarithmic or original variables. Therefore, the final analyses were performed using the latter.

Gender, age, ethnicity, family income, and type of trauma were examined in relation to early child and therapist alliance in five ANOVAs, as well as to both internalizing and externalizing symptoms at pre-assessment and improvement in internalizing and externalizing symptoms following treatment. Gender emerged as the only significant demographic variable when therapist-reported alliance was entered as a dependent variable $(F(1,183)=5.74, p=.02)$ but was not significant in terms of initial symptomatology or post-treatment change in symptoms. Girls were reported as having a more positive early alliance $(M=39.67, S D=5.37)$ than boys $(M=35.69, S D=6.36)$. Change in symptomatology did not seem to vary as a function of demographic variables. Due to the high co-occurring trauma experiences in this sample, single types of trauma could not be examined. Participants who completed therapy $(n=42)$ were compared to those who withdrew before completion $(n=53)$ with respect to internalizing and externalizing symptoms using independent $t$ tests, but no significant differences were found.

Correlations were calculated among child alliance, therapist alliance, internalizing symptoms, and externalizing symptoms to determine the relationships among these variables (see Table 2). Child and therapist alliance were positively correlated and significant correlations ranged from .30 to .58 . Child-reported alliance at time 2 and time 3 was positively correlated with improvement in internalizing symptoms. Pre-assessment internalizing and externalizing symptoms were positively correlated but not significantly correlated with gender. Give the wide age range in the sample, age was also included in the correlation analyses but no significant results were observed.

To assess the relationships among multiple independent and dependent variables simultaneously, a structural equation modeling analysis was conducted with the software Amos (Arbuckle, 2011). Missing data were addressed using the maximum likelihood estimation method (Allison, 1987), which uses all observed scores. A multilevel structural equation modeling in which the associations between alliance and change in symptomatology would be nested within gender could not be 
Table 2

Intercorrelations among the alliance and symptomatology variables.

\begin{tabular}{|c|c|c|c|c|c|c|c|c|c|c|c|c|}
\hline & 1 & 2 & 3 & 4 & 5 & 6 & 7 & 8 & 9 & 10 & 11 & 12 \\
\hline 1. Gender & 1 & & & & & & & & & & & \\
\hline 2. Age & -.18 & 1 & & & & & & & & & & \\
\hline 3. Child alliance 1 & -.22 & -.11 & 1 & & & & & & & & & \\
\hline 4. Child alliance 2 & $-.29^{*}$ & .07 & $.52^{* *}$ & 1 & & & & & & & & \\
\hline 5. Child alliance 3 & $-.42^{* *}$ & -.05 & $.62^{* *}$ & $.49^{* *}$ & 1 & & & & & & & \\
\hline 6 . Therapist alliance 1 & $-.30^{*}$ & -.01 & $.30^{*}$ & .22 & $.35^{*}$ & 1 & & & & & & \\
\hline 7. Therapist alliance 2 & $-.43^{* *}$ & -.09 & $.35^{* *}$ & $.58^{* *}$ & $.45^{* *}$ & $.71^{* *}$ & 1 & & & & & \\
\hline 8. Therapist alliance 3 & $-.51^{* *}$ & -.24 & $.30^{*}$ & $.43^{* *}$ & $.32^{*}$ & $.62^{* *}$ & $.76^{* *}$ & 1 & & & & \\
\hline $\begin{array}{l}\text { 9. Internalizing symptoms (log) } \\
\text { (pre-assessment) }\end{array}$ & .01 & .11 & .05 & .13 & .13 & .20 & .14 & .07 & 1 & & & \\
\hline $\begin{array}{l}\text { 10. Externalizing symptoms } \\
\text { (pre-assessment) }\end{array}$ & .18 & -.15 & -.09 & .02 & -.07 & -.10 & -.18 & -.15 & $.54^{* *}$ & 1 & & \\
\hline $\begin{array}{l}\text { 11. Internalizing symptoms (log) } \\
\text { (change at post-therapy) }\end{array}$ & -.07 & .24 & $.32^{*}$ & $.43^{* *}$ & .27 & .21 & .06 & .19 & .22 & .16 & 1 & \\
\hline $\begin{array}{l}\text { 12. Externalizing symptoms } \\
\text { (change at post-therapy) }\end{array}$ & .07 & -.02 & .14 & .26 & .18 & .27 & .01 & .14 & .28 & $.48^{* *}$ & $.55^{* *}$ & 1 \\
\hline
\end{tabular}

* Correlation is significant at the 0.05 level (2-tailed).

** Correlation is significant at the 0.01 level (2-tailed).

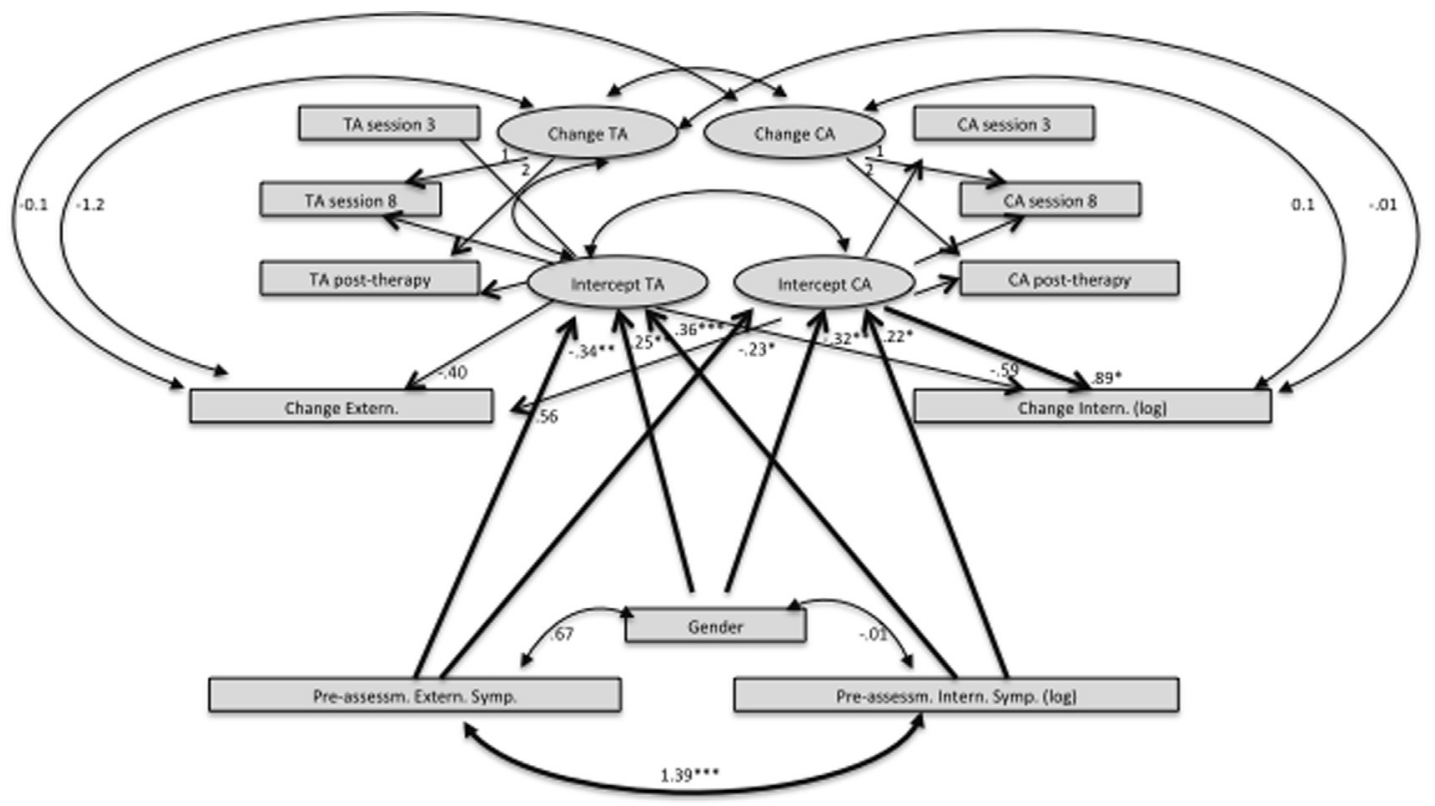

Fig. 1. Relationships between alliance and symptomatology. $C A=$ child alliance; $T A=$ therapist alliance; Pre-Assessm. Inter. Symp. (log) =internalizing symptoms measured at pre-assessment (logarithm transformation); Pre-Assessm. Exter. Symp.= externalizing symptoms measured at pre-assessment; Change Inter. Symp. $(\log )=$ change in internalizing symptoms measured at post-therapy (logarithm transformation); Change Exter. Symp.=change in externalizing symptoms measured at post-therapy; Gender = child gender. *Note. Arrows in bold represent significant relationships. Errors were removed from the original model for better readability.

conducted since we did not have the minimum sample size recommended (i.e., at least 60) at post-therapy (Eliason, 1993). The hypothesized model is presented in Fig. 1, and follows the standard parameterization for a latent growth model.

\section{Early Alliance and Change in Alliance}

The intercept latent variables represent the baseline therapeutic alliance scores for child (Intercept CA) and therapist (Intercept TA) at session 3, since the loading for change in alliance for child (Change CA) and therapist (Change TA) is zero for this time point. Each of the child and therapist session scores had a fixed loading of one on the intercept. The change in alliance latent variables represents the average change in scores across the three time points for child alliance (Change CA) and therapist alliance (Change TA). The loadings for the child and therapist alliance variables on the change (slope) latent variables were fixed at 0 (Session 3), 1 (Session 8) and 2 (Post-Therapy). Since early therapist alliance varied as a function of gender, this variable was examined in the current model (Fig. 1). 
Table 3

Summary of regression analyses for predicting alliance and improvement in symptoms.

\begin{tabular}{|c|c|c|c|c|}
\hline Predictor & Outcome variable & B & SE & $p$ \\
\hline Internalizing (pre-assessment) & Child alliance 1 & .22 & 1.67 & .04 \\
\hline Internalizing (pre-assessment) & Therapist alliance 1 & .25 & 2.10 & .03 \\
\hline Externalizing (pre-assessment) & Child alliance 1 & -.23 & .06 & .04 \\
\hline Externalizing (pre-assessment) & Therapist alliance 1 & -.34 & .08 & ${ }^{* *}$ \\
\hline Child alliance 1 & Change internalizing & .89 & .03 & .04 \\
\hline Therapist alliance 1 & Change internalizing & -.59 & .03 & .27 \\
\hline Child alliance 1 & Change externalizing & .56 & .73 & .17 \\
\hline Therapist alliance 1 & Change externalizing & -.40 & .72 & .49 \\
\hline Gender & Child alliance 1 & -.32 & 1.00 & ${ }^{* *}$ \\
\hline Gender & Therapist alliance 1 & -.36 & 1.30 & *** \\
\hline
\end{tabular}

Note. Child Alliance 1 = child alliance at session 3 (time point 1 ); Therapist Alliance 1 = therapist alliance at session 3 (time point 1 ).

$\chi^{2}(29, N=95)=36.47,(p=.16)$, CFI $=.97$, RMSEA $=.04$.

Child alliance $1: R^{2}=.18$, therapist alliance $1: R^{2}=.27$, change in internalizing: $R^{2}=.20$.

** $p<.01$.

$p<.001$.

\section{Improvement in Symptomatology}

As a preliminary analysis, a mixed model analysis for repeated measures was conducted to check for changes in symptomatology over time. Results indicated that both internalizing symptoms (logarithm) $[F(3,119)=5.29, p=.002]$ and externalizing symptoms $[F(3,116)=5.29, p=.017]$ improved significantly over time. Post hoc analyses revealed statistically significant differences in internalizing symptoms when pre-assessment $(M=1.07, S D=.33)$ was compared to post-therapy $(M=.88, S D=.37)$ and 6-month follow-up $(M=.84, S D=.38)$. In terms of externalizing symptoms, post hoc analyses revealed a significant difference when pre-assessment $(M=13.25, S D=8.65)$ and post-therapy $(M=9.52, S D=7.53)$ were compared.

Considering that no significant changes occurred when pre-therapy data were compared to data at other time points and that we had a reduced sample size at follow-up due to attrition, a decision was made to only include pre-assessment and post-therapy data in the analyses.

Improvement in internalizing and externalizing symptoms was obtained using the gain scores method, which is a reliable and unbiased measure of true change (Cribbie \& Jamieson, 2000; Rogosa, 1988) and equivalent to the slope factor from a latent growth model with two time points (Duncan, Duncan, Strycker, Li, \& Alpert, 1999). Symptom improvement was calculated by subtracting post-therapy scores from pre-assessment scores. Higher change score represent greater improvement.

\section{Model Fit}

Model fit was assessed by three measures: chi-square test $\left(\chi^{2}\right)$, the comparative fit index (CFI), and the root mean square of approximation (RMSEA). The measurement model fit the data well $\left[\chi^{2}(29, N=95)=36.47,(p=.16), \mathrm{CFI}=.97, \mathrm{RMSEA}=.04\right]$ since the recommended cut-offs for these measures are: a non-significant chi-square test, a CFI value of .95 and above, and a RMSEA value of less than .06 (Hooper, Coughlan, \& Mullen, 2008).

Early alliance. Gender was found to predict both early child-reported alliance (CA intercept; $\beta=-.32, p=.004$ ) and early therapist alliance (TA intercept; $\beta=-.37, p<.001$ ), with females having a more positive alliance than males. As hypothesized, both internalizing and externalizing symptoms predicted early alliance in opposite directions. Higher internalizing symptoms at pre-assessment predicted higher ratings of alliance for both child alliance $(\beta=.22, p=.04)$ and therapist alliance $(\beta=.25, p=.03)$. Higher externalizing symptoms predicted lower ratings of alliance for both child $(\beta=-.23, p=.04)$ and therapist $(\beta=-.34, p=.004)$. Eighteen percent of the variance in early child alliance and 27 percent of the variance in early therapist alliance can be accounted for by baseline internalizing and externalizing symptoms and gender. A similar pattern emerged when these relationships were examined separately by gender.

Early alliance and symptomatology. Early alliance was a predictor of improvement in internalizing symptoms after therapy $(\beta=.89, p=.04)$ and higher ratings of early alliance were associated with greater positive improvement post-treatment $(r=.32)$. Early alliance did not predict improvement in externalizing symptoms at the end of treatment. Twenty percent of the variance in change in internalizing symptoms $\left(R^{2}=.20\right)$ can be accounted for by early child-reported alliance (intercept CA) and therapist-reported alliance (intercept TA; see Table 3).

Change in alliance and symptomatology improvement. Contrary to our expectations, the relationship between change in alliance and change in symptomatology was not significant.

\section{Discussion}

The current study examined whether child's psychopathology prior to assessment predicted a positive therapeutic alliance early in treatment, and the association between therapeutic alliance and outcome in a Trauma-Focused Cognitive Behavioral Therapy program implemented in community mental health agencies. Our findings suggest that symptomatology 
and child gender are important factors impacting alliance at the beginning of treatment. Eighteen percent of the variance in child alliance and twenty-seven percent of the variance in therapist alliance was explained by the child's psychopathology and gender. Early alliance was also a predictor of improvement in internalizing symptoms, with twenty percent of the variance in improvement in internalizing symptomatology being attributed to child and therapist alliances.

Consistent with previous studies (Hawley \& Garland, 2008; Shirk \& Karver, 2003), child and therapist ratings of alliance were moderately correlated $(r=.30)$ at the beginning of treatment, which may suggest that child's and therapist's constructs of alliance overlap but also involve distinct processes. The mean ratings of early alliance were 42.31 and 38.66 , for children and therapists respectively, and the possible maximum score is 48 . This restricted range in the alliance data may have lowered the magnitude of the correlations (Hays, 1988) and reduced the probability of finding a significant association between change in alliance and improvement in symptomatology as we originally hypothesized.

As hypothesized, higher internalizing problems prior to therapy predicted stronger alliances and higher externalizing problems predicted weaker alliances early in treatment. Children showing more internalizing symptoms perceived the therapist as more helpful, understanding, and as working toward the same goals in therapy. On the other hand, highly externalizing children reported poorer early alliance. Given that alliance ratings for children and therapists were positively correlated, children's presenting problems early in therapy may have impacted how both child and therapist perceived and engaged in the therapeutic relationship. Nevertheless, these results should be interpreted with caution given the modest correlation between child's and therapist's reports. It is possible that while therapists may have responded more positively to internalizing children, they faced greater challenges connecting with externalizing children early on. To increase their sense of safety within the therapeutic context and willingness to engage in the therapy tasks, it may be necessary for therapists to spend more time establishing a strong alliance. Some strategies have been found to facilitate alliance building. A strengthbased approach in which the therapist honors the child's inner strengths and resources when faced with challenges has received increasing attention in the child and family treatment literature (Allison et al., 2003; Corcoran, 2005). Working collaboratively has been found to be paramount in developing a positive early child alliance in CBT for anxiety, while pushing the child to talk predicted early child alliance negatively (Creed \& Kendall, 2005). Moreover, therapists' characteristics such as warmth (Shirk \& Karver, 2003) and authenticity (Thompson, Bender, Lantry, \& Flynn, 2007) all have appeared to foster a positive alliance.

Although gender was not part of our original hypotheses, it emerged as a significant predictor of both child and therapist alliance, with females developing a more positive early alliance than males. It is important to note that of the 34 participating therapists, only one was male. Thus, gender mismatch may have contributed to the relational processes occurring in therapy. Research has shown that female therapists engage in the therapeutic relationship in a way that is more familiar and engaging to girls (Wintersteen, Mesinger, \& Diamond, 2005). Moreover, our sample had a large number of sexually abused girls, who tend to feel safer when treated by a female (Fowler \& Wagner, 1993). It has also been suggested that "action-oriented" activities (e.g., play, art) better reflect boys' relational style and could facilitate their engagement in the therapeutic relationship and tasks (Haen, 2011; Kiselica \& Englar-Carlson, 2008).

The relationship between early alliance and pre-assessment symptomatology did not seem to vary across gender. Research has shown that boys tend to exhibit more externalizing behaviors and that internalizing problems are more common among girls (Zhan-Waxler, 1993). However, no significant differences in internalizing and externalizing problems as a function of gender were found in our sample. This is consistent with clinical reports suggesting that sexually abused boys often present a wide variety of symptoms, which may include both internalizing and externalizing symptoms (Friedrich, 1995). The type of trauma and the presence of multiple traumas may also be a key element to understanding symptomatology manifestation. For example, a recent study with maltreated youth revealed that those who had experienced sexual abuse in combination with emotional abuse and/or neglect showed more elevated externalizing problems than those who had experienced sexual abuse alone (Mills et al., 2013).

Our hypothesis that stronger early alliances would predict improvement in symptoms was partially confirmed. Children who developed stronger alliance early in treatment, according to the child's report, showed greater improvement only in internalizing symptomatology following treatment, and the strength of this relationship was in the medium range $(r=.32)$. Unlike what has been shown in a meta-analytic review of child alliance studies (Shirk \& Karver, 2003), our findings did not indicate that alliance reports from treatment providers were more strongly associated with outcome. We could infer that client report of their sense of connection and safety within the therapeutic relationship in trauma therapy may be as important for children as it is for adults. Given that internalizing children in our study reported strong early alliances, it may be that these children were able to engage in the therapeutic relationship and perceived it positively in part due to the nature of their symptomatology. This in turn may have allowed for active engagement in therapy tasks and subsequent improved skills to cope with their symptomatology.

No relationship between early alliances and change in externalizing symptoms was observed. It may be that the relationship between alliance and improvement in externalizing symptoms is more complex in maltreated children. It may also be that parental factors play a role in outcome. Deblinger et al. (2011) showed that children whose parents attended more sessions in a TF-CBT program showed greater improvement in parenting practices and reduction in externalizing symptomatology. Maternal depression was also linked to children's externalizing behaviors and it was suggested that caregiver-therapist alliance mediates the relationship between child alliance and improvement in externalizing behaviors (Granic et al., 2012). Finally, it is important to take into account the challenges of comparing data from multiple raters. Low levels of agreement between children and their caregivers on the child's problems have been reported (Hawley \& Weisz, 
2003; De Los Reyes \& Kazdin, 2005) and parent-child discordance may be a key factor when studying associations between alliance and symptomatology.

The initial TF-CBT session is devoted to psychoeducation on trauma and covers delicate material that may elicit intense reactions in children, which could potentially impact early alliance. However by the time alliance questionnaires were completed, treatment would have focused on developing affect regulation and cognitive processing skills. It is reasonable to conclude that our findings regarding early alliance may be generalized to other evidence-based child therapies that aim at developing such skills as part of their overarching treatment goals.

\section{Limitations of the Study}

Despite some meaningful findings, the study has a number of limitations. First, we only examined parent report of psychopathology. Further research is needed to determine the relationships between child report of psychopathology and alliance. Second, our study focused solely on the relationship between child and therapist. Recent findings have highlighted the importance of parent's alliance and involvement in TF-CBT. Future research should examine the extent to which parent's alliance is important to the outcome of this therapeutic modality. Third, while recognizing the importance of comparison groups, we had to stop assigning participants to a control group in early stages of the study due to an agency policy changes. Thus the effect of passage of time in the results obtained could not be assessed. Fourth, because this was a community-based study and the agencies could not enable recording of therapy sessions, a more reliable independently coded adherence checklist to evaluate model fidelity was not completed. Instead, a therapist self-report questionnaire with mainly educational purposes was used. Fifth, a nested design testing therapist and agency effects could not be conducted given the insufficient number for any given group. Finally, replication of this study could be enhanced by examining the impact of trauma-related psychopathology on alliance and to what extent the relationship between alliance and outcome may vary as function of gender and severity of trauma symptoms.

\section{Acknowledgments}

The authors acknowledge the following children's mental health centers for their participation in this clinical research study: Aisling Discoveries Child and Family Center, Boost Child Abuse Prevention and Intervention, Child Development Institute, COSTI Family and Mental Health Services, The Etobicoke Children's Center, The Hincks-Dellcrest Treatment Center (Sheppard Site), The Hincks-Dellcrest Treatment Center (Jarvis Site), Yorktown Child and Family Center, and Peel Children's Center.

\section{References}

Achenbach, T. M., Howell, C. T., McConaughy, S. H., \& Stanger, C. (1998). Six-year predictors of problems in a national sample: IV. Young adult signs of disturbance. Journal of the American Academy of Child E'Adolescent Psychiatry, 37, 718-727.

Achenbach, T. M., \& Rescorla, L. A. (2001). Manual for the ASEBA school-age forms and profiles. Burlington, VT: University of Vermont, Research Center for Children, Youth and Families.

Allison, S., Stacey, K., Dadds, V., Roeger, L., Wood, A., \& Martin, G. (2003). What the family brings: Gathering evidence for strengths-based work. Journal of Family Therapy, 25, 263-284

Allison, P. D. (1987). Estimation of linear models with incomplete data. In C. C. Clogg (Ed.), Sociological methodology (pp. 71-103). San Francisco: Jossey-Bass. Arbuckle, J. L. (2011). IBM SPSS Amos (Version 20.0). Chicago: SPSS.

Bickman, L., Andrade, A., Athay, M., Chen, J., de Nadai, A. S., Jordan-Arthur, B., \& Karver, M. (2012). The relationship between change in therapeutic alliance ratings and improvement in youth symptom severity: Whose ratings matter the most? Administration and Policy in Mental Health and Mental Health Services Research, 39, 78-89.

Bolger, K. E., \& Patterson, C. J. (2001). Pathways from child maltreatment to internalizing problems: Perceptions of control as mediators and moderators. Development and Psychopathology, 13(4), 913-940. http://dx.doi.org/10.1037/0003-066x.47.12.1597

Bordin, E. S. (1979). The generalizability of the psychoanalytic concept of working alliance. Psychotherapy: Theory, Research, and Practice, 16, 252-260.

Cary, C. E., \& McMillen, J. C. (2012). The data behind the dissemination: A systematic review of trauma-focused cognitive behavioral therapy for use with children and youth. Children and Youth Services Review, 34(4), 748-757. http://dx.doi.org/10.1016/j.childyouth.2012.01.003

Chiu, A. W., McLeod, B. D., Har, K., \& Wood, J. J. (2009). Child-therapist alliance and clinical outcomes in cognitive behavioural therapy for child anxiety disorders. Journal of Child Psychology and Psychiatry, 50, 751-758. http://dx.doi.org/10.1111/j.1469-7610.2008.01996.x

Chu, B. C., Choudhury, M. S., Shortt, A. L., Pincus, D. B., Creed, T. A., \& Kendall, P. C. (2004). Alliance, technology, and outcome in the treatment of anxious youth. Cognitive and Behavioral Practice, 11, 44-55.

Chu, B. C., \& Kendall, P. C. (2004). Positive association of child involvement and treatment outcome within a manual-based cognitive-behavioral treatment for children with anxiety. Journal of Consulting and Clinical Psychology, 5, 821-829. http://dx.doi.org/10.1037/0022-006X.72.5.821

Chu, B. C., Skriner, L. C., \& Zandberg, L. J. (2014). Trajectory and predictors of alliance in cognitive behavioral therapy for youth anxiety. Journal of Clinical Child and Adolescent Psychology, 43, 721-734. http://dx.doi.org/10.1080/15374416.2013.785358

Cicchetti, D., \& Toth, S. L. (1995). A developmental psychopathology perspective on child abuse and neglect. Journal of the American Academy of Child E Adolescent Psychiatry, 34(5), 541-565. http://dx.doi.org/10.1097/00004583-199505000-00008

Cicchetti, D., \& Toth, S. L. (2005). Child maltreatment. Annual Review of Clinical Psychology, 1, 409-438.

Cloitre, M., Cohen, L. R., \& Scarvalone, P. (2002). Understanding revictimization among childhood sexual abuse survivors: An interpersonal schema approach. Journal of Cognitive Psychotherapy: An International Quarterly, 16, 91-111.

Cloitre, M., Koenen, K. C., Cohen, L. R., \& Han, H.(2002). Skills training in affective and interpersonal regulation followed by exposure: A phase based treatment for PTSD related to childhood abuse. Journal of Consulting and Clinical Psychology, 70, 1067-1074. http://dx.doi.org/10.1037/0022-006X.70.5.1067

Cloitre, M., Stovall-McClough, K. C., Miranda, R., \& Chemtob, C. M. (2004). Therapeutic alliance, negative mood regulation, and treatment outcome in child abuse-related posttraumatic stress disorder. Journal of Consulting and Clinical Psychology, 72, 411-416. http://dx.doi.org/10.1037/0022-006X.72.411

Cohen, J. A., Deblinger, E., Mannarino, A. P., \& Steer, R. A. (2004). A multi-site, randomized controlled trial for sexually abused children with PTSD symptoms. Journal of the American Academy of Child and Adolescent Psychiatry, 43, 393-402. 
Cohen, J. A., \& Mannarino, A. P. (1998). Interventions for sexually abused children: Initial treatment outcome findings. Child Maltreatment, 3, 17-26.

Cohen, J. A., Mannarino, A. P., \& Deblinger, E. (2006). Treating trauma and traumatic grief in children E' adolescents. New York: Guilford Press.

Cohen, J. A., Mannarino, A. P., \& Knudsen, K. (2005). Treating sexually abused children: One-year follow-up of a randomized controlled trial. Child Abuse E Neglect, 29, 135-145.

Corcoran, J. (2005). Building strengths and skills: A collaborative approach to working with clients. New York: Oxford University Press.

Creed, T. A., \& Kendall, P. C. (2005). Therapist alliance-building behaviour within a cognitive-behavioral treatment for anxiety in youth. Journal of Consulting and Clinical Psychology, 73, 498-505.

Cribbie, R. A., \& Jamieson, J. (2000). Structural equation models and the regression bias for measuring correlates of change. Educational and Psychological Measurement, 60, 893-907.

Dalenberg, C. J. (2000). Countertransference and the treatment of trauma. Washington, DC: American Psychological Association.

Deblinger, E., Mannarino, A. P., Cohen, J. E., Runyon, M. K., \& Steer, R. A. (2011). Trauma-focused cognitive behavioral therapy for children: Impact of the trauma narrative and treatment length. Depression and Anxiety, 28, 67-75. http://dx.doi.org/10.1002/da.20744

Deblinger, E., Steer, R. A., \& Lippmann, J. (1999). Two-year follow-up study of cognitive behavioral therapy for sexually abused children suffering posttraumatic stress symptoms. Child Abuse and Neglect, 23, 1371-1378.

De Los Reyes, A., \& Kazdin, A. E. (2005). Informant discrepancies in assessing child dysfunction relate to dysfunction within mother-child interaction. Journal of Child E' Family Studies, 15, 645-663. http://dx.doi.org/10.1007/s10826-006-9031-3

DiGiuseppe, R., Linscott, J., \& Jilton, R. (1996). Developing the therapeutic alliance in child-adolescent psychotherapy. Applied and Preventive Psychology, 5, $85-100$

Duncan, T. E., Duncan, S. C., Strycker, L. A., Li, F., \& Alpert, A. (1999). An introduction to latent variable growth curve modeling: Concepts, issues, and applications. Mahwah, NJ: Lawrence Erlbaum Associates, Publishers.

Eliason, S. R. (1993). Maximum Likelihood Estimation: Logic and practice. Newbury Park, CA: Sage Publications, Inc.

Eltz, M. J., Shirk, S. R., \& Sarlin, N. (1995). Alliance formation and treatment outcome among maltreated adolescents. Child Abuse and Neglect, 19, 419-431.

Finkelhor, D., Ormrod, R. K., Turner, H. A., \& Hamby, S. L. (2005). Measuring poly-victimization using the JVQ. Child Abuse and Neglect, 29, 1297-1312.

Florsheim, P., Shotorbani, S., Guest-Warnick, G., Barratt, T., \& Wei-Chin, H. (2000). Role of the working alliance in the treatment of delinquent boys in community-based programs. Journal of Clinical Child Psychology, 29, 94-107.

Fowler, W. E., \& Wagner, W. G. (1993). Preference for and comfort with male versus female counselors among sexually abused girls in individual treatment. Journal of Counseling Psychology, 40, 65-72.

Friedrich, W. N. (1995). Psychotherapy with sexually abused boys. Thousand Oaks, CA: Sage Publications, Inc.

Garcia, J. A., \& Weisz, J. R. (2002). When youth mental health care stops: Therapeutic relationship problems and other reasons for ending youth outpatient treatment. Journal of Consulting and Clinical Psychology, 70, 439-443. http://dx.doi.org/10.107//0022-006X.70.2.439

Granic, I., Oten, R., Engels, R. C. M. E., Blokland, K., Solomon, T., \& Ferguson, B. (2012). Maternal depression mediates the link between therapeutic alliance and improvements in adolescent externalizing behavior. Journal of Family Psychology, 26, 880-885. http://dx.doi.org/10.1037/a0030716

Green, J. (2006). Annotation: The therapeutic alliance - A significant but neglected variable in child mental health treatment studies. Journal of Child Psychology and Psychiatry, 47, 425-435. http://dx.doi.org/10.1111/j.1469-7610.2005.01516.x

Haen, C. (2011). Engaging boys in treatment: Creative approaches to the therapy process. New York: Routledge.

Hawley, K. M., \& Garland, A. F. (2008). Working alliance in adolescent outpatient therapy: Youth, parent, and therapist reports and associations with therapy outcomes. Child and Youth Care Forum, 37, 59-74. http://dx.doi.org/10.1007/s10566-008-9050-X

Hawley, K. M., \& Weisz, J. R. (2005). Youth versus parent working alliance in usual clinical care: Distinctive associations with retention, satisfaction and treatment outcome. Journal of Clinical Child and Adolescent Psychology, 34, 117-128.

Hawley, K. M., \& Weisz, J. R. (2003). Child, parent, and therapist (dis)agreement in target problems in outpatient therapy: The therapist's dilemma's and its implications. Journal of Consulting and Clinical Psychology, 71, 62-70. http://dx.doi.org/10.1037/0022-006X.71.1.62

Hays, W. L. (1988). Statistics (4th ed.). New York: Holt, Rinehart, and Winston.

Hogue, A., Dauber, S., Stambaugh, L. F., Cecero, J. J., \& Liddle, H. A. (2006). Early therapeutic alliance and treatment outcome in individual and family therapy for adolescent behavior problems. Journal of Consulting and Clinical Psychology, 74, 121-129. http://dx.doi.org/10.1037/0022-006X.74.1.121

Hooper, D., Coughlan, J., \& Mullen, M. (2008). Structure equation modelling: Guidelines for determining model fit. Electronic Journal of Business Research Methods, 6, 53-60.

Horvath, A. O., \& Luborsky, L. (1993). The role of the therapeutic alliance in psychotherapy. Journal of Consulting and Clinical Psychology, 61, 561-573.

Kazdin, A. E., \& Durbin, K. A. (2012). Predictors of child-therapist alliance in cognitive-behavioral treatment of children referred for oppositional and antisocial behavior. Psychotherapy, 49, 202-217.

Keller, S. M., Zoellner, L. A., \& Feeny, N. C. (2010). Understanding factors associated with early therapeutic alliance in PTSD treatment: Adherence, childhood sexual abuse history and social support. Journal of Consulting and Clinical Psychology, 78, 974-979. http://dx.doi.org/10.1037/a0020758

Kendall, P. C. (1994). Treating anxiety disorders in children: Results of a randomized clinical trial. Journal of Consulting and Clinical Psychology, 62, 100-110.

Kendall, P. C., Comer, J. S., Marker, C. D., Creed, T. A., Puliafico, A. C., Hughes, A. A., Martin, E., Suveg, C., \& Hudson, J. L. (2009). In-session exposure tasks and therapeutic alliance across the treatment of childhood anxiety disorders. Journal of Consulting and Clinical Psychology, 77, 517-525. http://dx.doi.org/10.1037/a0013686

Kiselica, M. S., \& Englar-Carlson, M. (2008). Establishing rapport with boys in individual counseling and psychotherapy: A male friendly perspective. In M. S. Kiselica, M. Englar-Carlson, \& A. M. Horne (Eds.), Counseling troubled boys: A guidebook for professionals (pp. 49-65). New York: Routledge.

Konanur, S., Muller, R. T., Cinamon, J. S., Thornback, K., \& Zorzella, K. P. M. (2015). Effectiveness of Trauma-Focused Cognitive Behavioral Therapy in a community-based program. Child Abuse and Neglect (in press).

Liber, J. M., McLeod, B. D., Van Windenfelt, B. M., Goedhart, A. W., Van der Leeden, A. J. M., Utens, E. M. W. J., \& Treffers, P. D. A. (2010). Examining the relation between the therapeutic alliance, treatment adherence, and outcome of cognitive behavioral therapy for children with anxiety disorders. Behavior Therapy, 41, 172-186.

Manly, J. T., Kim, J. E., Rogosch, F. A., \& Cicchetti, D. (2001). Dimensions of child maltreatment and children's adjustment: Contributions of developmental timing and subtype. Development and Psychopathology, 13(4), 759-782. http://dx.doi.org/10.1037/0033-2909.113.1.164

Martin, D. J., Garske, J. P., \& Davis, M. K. (2000). Relationship of the therapeutic alliance with outcome and other variables: A meta-analytic review. Journal of Consulting and Clinical Psychology, 68, 438-450.

Masten, A. S., \& Cicchetti, D. (2010). Developmental cascades. Development and Psychopathology, 22, 491-495. http://dx.doi.org/10.1017/ S0954579410000222

McCrory, E., De Brito, S. A., \& Viding, E. (2010). Research review: The neurobiology and genetics of maltreatment and adversity. Journal of Child Psychology and Psychiatry, 51, 1079-1095. http://dx.doi.org/10.1111/j.1469-7610.2010.02271.x

McLeod, B., \& Weisz, J. (2005). The therapy process observational coding scale: Measure characteristics and prediction of outcomes in usual clinical practice. Journal of Consulting and Clinical Psychology, 73, 323-333.

McLewin, L. (2010). Exploration of factors influencing the early therapeutic alliance in a treatment program for child trauma (Unpublished doctoral dissertation). York University, Toronto, Ontario.

Mills, R., Scott, J., Alati, R., O'Callaghan, M., Najman, J. M., \& Stratheam, L. (2013). Child maltreatment and adolescent mental health problems in a large birth cohort. Child Abuse \&' Neglect, 37, 292-302.

Moylan, C. A., Herrenkohl, T. I., Sousa, C., Tajima, E. A., Herrenkohl, R. C., \& Russo, M. J. (2010). The effects of child abuse and exposure to domestic violence on adolescent internalizing and externalizing behavior problems. Journal of Family Violence, 25(1), 53-63. http://dx.doi.org/10.1007/s10896-009-9269-9 
Muller, R. T., \& Di Paolo, M. A. (2008). The healthy coping program for maltreated children. Ottawa, Canada: Provincial Centre of Excellence, Child \& Youth Mental Health at CHEO: Research Grant.

Muller, R. T., Padoin, C., \& Lawford, J. (2008). Trauma-focused cognitive-behavioral therapy with children and adolescents: The Toronto-community based approach. In A. V. Cordioli (Ed.), Psicoterapias: Abordagens atuais. Porto Alegre: Artmed.

Ormaugh, S. M., Jensen, T. K., Wentzel-Larsen, T., \& Shirk, S. S. (2013). The therapeutic alliance in treatment of traumatized youth: Relation to outcome in a randomized clinical trial. Journal of Consulting and Clinical Psychology, http://dx.doi.org/10.1037/a0033884

Rogosa, D. (1988). Myths about longitudinal research. In K. W. Schaie, R. T. Campbell, W. M. Meredith, \& S. C. Rawlings (Eds.), Methodological issues in aging research (3rd ed., pp. 171-209). New York, NY: Springer.

Shirk, S. R., Gundmundsen, G., Kaplinski, H. C., \& McMakin, D. L. (2008). Alliance and outcome in cognitive-behavioral therapy for adolescent depression. Journal of Clinical Child and Adolescent Psychology, 37, 631-639. http://dx.doi.org/10.1080/15374410802148061

Shirk, S. R., \& Karver, M. (2003). Prediction of treatment outcome from relationship variables in child and adolescent therapy: A meta-analytic review. Journal of Consulting and Clinical Psychology, 71, 452-464.

Shirk, S. R., Karver, M. S., \& Brown, R. (2011). The alliance in child and adolescent psychotherapy. Psychotherapy, 48, 17-24. http://dx.doi.org/ $10.1037 / \mathrm{a} 0022181$

Shirk, S. R., \& Saitz, C. C. (1992). Clinical, empirical, and developmental perspectives on the therapeutic relationship in child psychotherapy. Development and Psychopathology, 4, 713-728.

Teisl, M., \& Cicchetti, D. (2008). Physical abuse, cognitive and emotional processes, and aggressive/disruptive behavior problems. Social Development, 17, $1-23$.

Thompson, S. J., Bender, K., Lantry, J., \& Flynn, P. M. (2007). Treatment engagement: Building therapeutic alliance in home-based treatment with adolescents and their families. Contemporary Family Therapy Journal, 29, 39-55.

Wintersteen, M., Mesinger, J., \& Diamond, G. (2005). Do gender and racial differences between patient and therapist affect therapeutic alliance and treatment retention in adolescents? Professional Psychology: Research and Practice, 36, 400-408.

Zhan-Waxler, C. (1993). Warriors and worriers: Gender and psychopathology. Development and Psychopathology, 5, 79-89. 